\title{
Fundamentos pedagógicos de Língua Portuguesa na BNCC: uma análise crítica de discursos
}

\author{
Rosana Maria Schmitt* \\ Francieli Matzenbacher Pinton **
}

\section{Resumo}

Considerando a importância da Base Nacional Comum Curricular e sua influência no desenvolvimento de práticas pedagógicas em todo o país, neste relato de pesquisa, analisamos criticamente os discursos sobre ensino de língua portuguesa presentes nos fundamentos pedagógicos do componente curricular para os anos finais do Ensino Fundamental. Para tanto, orientamo-nos teórico-metodologicamente pela Análise Crítica de Discurso, que propõe uma análise tridimensional, com vistas à descrição da prática textual, à interpretação das práticas discursivas e à explicação das práticas sociais. Os resultados apontam um discurso sobre ensino de língua portuguesa, em grande medida, alinhado à perspectiva de gêneros discursivos/textuais que considera contextos situados e focaliza o desenvolvimento de práticas de usos de língua(gem). Importante ressaltar certa fluidez discursiva, visto que, por vezes, há o apagamento do gênero enquanto objeto de ensino, o que pode suscitar leituras enviesadas do documento e, consequentemente, subsidiar propostas pedagógicas que não contemplem a complexidade desse objeto.

Palavras-Chave: Base Nacional Comum Curricular; Ensino Fundamental; Ensino de Língua Portuguesa.

\section{Introdução}

\author{
A Base Nacional Comum Curricular \\ (BNCC), atual documento oficial da \\ educação, configura-se como parte da
}

\footnotetext{
Licenciada em Letras - Habilitação Português e Literaturas da Língua Portuguesa pela Universidade Federal de Santa Maria (2018) e Mestra em Letras - Estudos Linguísticos pela mesma instituição (2021). Atualmente, é aluna do Curso de Doutorado do Programa de Pós-Graduação em Letras - Estudos Linguísticos (PPGL/UFSM) e integrante do Núcleo de Estudos e Pesquisas em Ensino de Linguagem (NEPELIN). E-mail: rosanaschmitt30@gmail.com
}

** Graduação em Letras pela Universidade Regional Integrada do Alto Uruguai e das Missões - URI (1999), Mestrado (2003) e Doutorado (2012) em Letras pela Universidade Federal de Santa Maria (UFSM). Professora Adjunto A do Departamento de Letras Vernáculas do Centro de Artes e Letras e do Programa de Pós-graduação em Letras da Universidade Federal de Santa Maria (UFSM). Membro da Associação Latino-americana de linguística Sistêmico-funcional (ALSFAL), da Associação Latino-americana de Estudos da Escrita na Educação Superior e em Contextos Profissionais e do Grupo de Trabalho Gêneros Discursivos/textuais da ANPOLL. Coordenadora do Núcleo de Estudos e Pesquisas em Ensino de Linguagem (NEPELIN). Docente orientadora do Núcleo de Língua Portuguesa do Programa de Residência Pedagógica (2018-2020). Tem experiência em Análise Crítica de Gêneros textuais, formação de professores de língua portuguesa, ensino e leitura de produção textual em diferentes áreas disciplinares, ensino de língua portuguesa na educação básica. E-mail: francieli.matzembacher@gmail.com

\footnotetext{
Data de submissão: abr. 2021 - Data de aceite: jul. 2021 http://dx.doi.org/10.5335/rdes.v17i2.12610
} 
política nacional da Educação Básica e foi produzida com a finalidade de definir

[...] o conjunto orgânico e progressivo de aprendizagens essenciais que todos os alunos devem desenvolver ao longo das etapas e modalidades da Educação Básica, de modo a que tenham assegurados seus direitos de aprendizagem e desenvolvimento (BRASIL, 2018, p. 7).

Esse objetivo, sustentado com o argumento de que "educação é a base" e de que é por meio da BNCC que se pode garantir uma educação de qualidade, uma formação humana integral e a construção de uma sociedade justa, democrática e inclusiva, sinaliza o entendimento de que

[...] basta haver um currículo nacional único para que a aprendizagem seja supostamente homogeneizada em todo país, independentemente das especificidades e dificuldades de cada região, de cada contexto e de cada instituição (TÍLIO, 2019, p. 12).

Ainda que a BNCC não seja definida como currículo, partilhamos da mesma posição de Tílio (2019), Lourenço e Lino de Araújo (2019), Macedo (2017), entre diversos outros, de que ela pode, sim, ser entendida como um currículo mínimo, já que, na prática, é a principal referência nacional obrigatória para construí-lo. Considerando, então, que os discursos manifestados pelo documento ecoam no contexto escolar e influenciam diretamente a prática docente, visto que são uma forma de prática social por meio da qual as pessoas podem agir sobre $o$ mundo e sobre os outros (FAIRCLOUGH, 2001, p. 91), neste relato de pesquisa, propomo-nos a analisar criticamente os discursos sobre o ensino de língua portuguesa presentes nos fundamentos pedagógicos do componente curricular dos anos finais do ensino fundamental presentes na BNCC.

Para relatar os resultados desta pesquisa, organizamos este texto em três movimentos, além desta Introdução e das Considerações Finais, quais sejam: breve revisão da abordagem teórico-metodológica que compreende a Análise Crítica do Discurso (ACD), descrição do percurso metodológico e sumarização dos resultados das análises contextual e textual.

\section{Análise Crítica do Discurso}

A Análise Crítica do Discurso (ACD) é uma proposta teórico-metodológica para análise de discursos de modo linguisticamente orientado que busca estabelecer um quadro analítico capaz de subsidiar a investigação de contextos sociais específicos e mudanças sociais. Essa proposta foi cunhada por Norman Fairclough a partir de um artigo publicado no Journal of Pragmatics em 1985, e, anos depois, após a publicação de Language and Power (1989), começou a constituir-se enquanto teoria científica.

A abordagem de análise do discurso proposta por Fairclough baseia-se no 
pressuposto de que a linguagem é parte irredutível da sociedade e dialeticamente interligada a outros elementos da vida social, assim, questões sociais são, em parte, questões do discurso e vice-versa (FAIRCLOUGH, 2003). Logo, qualquer análise de textos que pretende ser significativa em termos científicos precisa se conectar com questões teóricas sobre o discurso. No entanto, não é possível compreender de forma efetiva os efeitos sociais do discurso sem considerar, também, o que acontece quando as pessoas falam ou escrevem, ou seja, sem levar em conta aspectos linguísticos. Para isso, o que a ACD propõe é uma análise do discurso linguisticamente orientada, em que as duas faces da análise discursiva - social e linguística - não podem ser separadas no trabalho analítico, visto que "o objetivo da análise é justamente mapear as conexões entre relações de poder e recursos linguísticos utilizados em textos" (RAMALHO; RESENDE, 2006, p. 9).

Por se ocupar com efeitos ideológicos que textos possam ter sobre relações sociais, ações e interações, conhecimentos, crenças, atitudes, valores e identidades, interessam à ACD investigações que relacionem o uso da linguagem a contextos situados. Essa postura assumida pela ACD conversa com uma concepção de linguagem como parte da prática social. Isso quer dizer que, diferentemente de outros estudos, não há uma preocupação de análise centrada somente na estrutura, ou seja, nas características mais fixas da linguagem, nem somente na ação social dos falantes, isto é, nos eventos mais flexíveis. A proposta da ACD é, justamente, partir do conceito de discurso e tomá-lo como central, já que ele se relaciona tanto com a estrutura - com a linguagem enquanto sistema -, quanto com o uso contextualizado desse sistema. O conceito de discurso é entendido como o "uso de linguagem como forma de prática social, [...] um modo de ação, uma forma em que as pessoas podem agir sobre o mundo e especialmente sobre os outros" (FAIRCLOUGH, 2001, p. 91). Desse modo, consideram-se as estruturações presentes na sociedade e o uso da linguagem de modo inter-relacionado e bidirecional.

Ainda que o principal material analítico com o qual os analistas de discurso trabalham seja o texto, o nível mais concreto dos eventos, o foco de análises críticas discursivas transita entre os três níveis da linguagem, visto que o trabalho de descrição, interpretação e explicação das relações entre linguagem e sociedade não pode ser feito, de modo satisfatório, apenas com base em análises textuais, pois "não devemos presumir que a realidade de textos seja exaurida por nosso conhecimento sobre eles" (FAIRCLOUGH, 2003, p. 14). Desse modo, as análises devem privilegiar o espaço das ordens do discurso a fim 
de (re)conhecer o funcionamento social da linguagem, dado que, para a ACD, o objeto de estudo é a linguagem enquanto prática social, e não simplesmente como estrutura ou texto.

Nessa perspectiva, o conceito de discurso é fundamental para compreender a concepção de linguagem enquanto prática social e instrumento de poder. É importante destacar que, conforme Fairclough (2001), o uso do discurso não está relacionado a uma atividade puramente individual, muito mais do que isso, refere-se a uma forma de significação, representação e ação, que contribui para a construção de identidades sociais, posições de sujeitos, relações sociais e sistemas de conhecimento e crença. Consequentemente, esse uso também contribui para reproduzir a sociedade e transformá-la.

Sendo a ACD uma proposta, além de teórica, também metodológica, Fairclough (2001) propõe um método de análise tridimensional que compreende três procedimentos sugeridos pela ACD: descrição, interpretação e explicação, os quais permitem considerar que qualquer evento discursivo seja, simultaneamente, um texto, um exemplo de prática discursiva e um exemplo de prática social. A dimensão do texto focaliza a análise linguística de textos, a dimensão da prática discursiva especifica a natureza dos processos de produção e interpretação textual e a dimensão da prática social engloba questões de interesse na análise social, tais como circunstâncias institucionais e organizacionais do evento discursivo.

Desse modo, para que se inicie uma possível transformação social por meio do discurso, é necessário enfatizarmos criticamente, enquanto analistas do discurso, os processos ideológicos envolvidos em discursos que partem de estruturas sociais abstratas, visto que analisar instituições e organizações em termos de poder diz respeito à compreensão de práticas discursivas dominantes e, consequentemente, à autonomia para contestá-las e modificá-las. Assim, propor um estudo que tem a ACD como base teórica e metodológica contribui, também,

[...] para que as pessoas possam tornar-se mais conscientes de sua própria prática e mais críticas de discursos investidos ideologicamente a que são submetidos (FAIRCLOUGH, 2001, p. 120).

\section{Percurso metodológico}

O universo desta investigação compreende a terceira e atual versão do documento oficial Base Nacional Comum Curricular que, contendo as três etapas da Educação Básica, foi homologado em dezembro de 2018. Desse documento, focalizamos, no componente curricular Língua Portuguesa - anos finais da etapa Ensino Fundamental -, as seções 
"4.1.1 Língua Portuguesa" (BRASIL, 2018) e "4.1.1.2 Língua Portuguesa no Ensino Fundamental - Anos Finais: práticas de linguagem, objetos de conhecimento e habilidades" (BRASIL, 2018).

$\mathrm{Na}$ dimensão da análise contextual, buscamos interpretar aspectos da prática discursiva, focalizando especialmente $o$ processo de produção do documento. Para investigar esse contexto, realizamos uma discussão sobre o processo de elaboração da BNCC, até chegar à terceira e atual versão, com base em informações coletadas: i) no próprio documento; ii) em sites vinculados à $\mathrm{BNCC}$ (tais como o site oficial do MEC e o site Movimento pela Base); iii) em estudos prévios que discutem e analisam os bastidores do processo.

$\mathrm{Na}$ dimensão textual, a fim de analisar criticamente os fundamentos pedagógicos do componente curricular Língua Portuguesa, utilizamos o método de análise que focaliza elementos ricos em significação (BARTON, 2004). A partir desse método, de acordo com Barton (2004), buscamos por características particulares no corpus, associadas a padrões de significado no contexto, que se tornam relevantes a partir do momento em que assumem, por meio de uma análise exploratória e inicialmente intuitiva, um padrão de ocorrência. Essas características são chamadas de recursos ricos em significação que, em outras palavras, são a base para compreender a relação entre um texto e seu contexto.
Para isso, foram adotados, com base em Barton (2004), os seguintes procedimentos analíticos: i) selecionar um corpus inicial que é relevante para dar conta do objetivo geral; ii) a partir de uma análise exploratória e inicialmente intuitiva, identificar padrões salientes, verificando ocorrências de características relevantes para o estudo; iii) determinar o que é "interessante" e selecionar um corpus de estudo (amostragem); iv) verificar o padrão (codificação, contagem e outras formas de análise empírica sem comprovação científica -, a partir da observação); v) desenvolver uma análise funcional-retórica (explicando o significado de um padrão em seu contexto); vi) apresentar os resultados da análise usando principalmente exemplos para relacionar as características identificadas com determinados discursos sobre ensino de língua portuguesa; vii) sugerir uma explicação sobre como a análise do discurso resultante é interessante para o campo da Linguística Aplicada, o que esses dados revelam e quais os próximos passos.

A partir desses procedimentos, identificamos, ao longo da análise, padrões semânticos salientes acerca dos discursos sobre ensino de língua portuguesa, a partir da constatação de ocorrências dos itens lexicais gênero(s) e (multi)letramentos $^{1} \mathrm{e}$, imbricados a eles, lexemas correspondentes aos seus respectivos campos semânticos. Com base nessa 
constatação inicial, evidenciamos características interessantes relacionadas a esses itens lexicais e selecionamos uma amostragem $^{2}$ de análise que compreende os excertos em que eles ocorrem no texto, a fim de verificar as categorias semânticas que comprovem os padrões identificados e auxiliem a compreensão crítica desses discursos.

\section{Análise e discussão dos resultados: contexto de produção}

De acordo com informações veiculadas no site oficial do Ministério da Educação (BRASIL, 2021) e no site Movimento pela Base (2021), o processo de construção do documento oficial iniciou em 2015, com a instituição da comissão de especialistas para a elaboração de proposta da BNCC, formada pelo Ministério da Educação (MEC) a partir da portaria $\mathrm{n}^{-}$ 592. Essa comissão acabou assumindo a responsabilidade de produzir as duas primeiras versões do documento ${ }^{3}$, sendo que a primeira versão foi disponibilizada para consulta pública três meses após a comissão ser instituída (setembro de 2015) e a segunda foi disponibilizada em maio do ano seguinte (2016). Nesse período, ocorreram diversos debates, conferências e possibilidade de participação da sociedade via portal on-line, porém, não foram encontradas elucidações sobre como e se as 12 milhões de contribuições foram consideradas no curto espaço de tempo entre a divulgação da primeira versão e a redação da segunda.

A segunda versão "rodou" o Brasil em 27 seminários estaduais de junho a agosto de 2016. Nesse período, em meio a um cenário de crise política - marcado pelo processo de impeachment contra a então presidenta Dilma Rousseff e pela ascensão de Michel Temer à Presidência da República -, ocorreu, em julho de 2016, a substituição integral da equipe de redação do documento que, no mês seguinte, já iniciou o processo de redação da terceira versão "em um processo colaborativo com base na versão 2" (BRASIL, 2020). Conforme veiculado no site oficial do MEC (BRASIL, 2020), além de ser elaborada com base na segunda versão, essa versão final também foi produzida em consonância com o relatório de contribuições ${ }^{4}$ dos seminários estaduais, organizado pelo Conselho Nacional de Secretários de Educação (CONSED) e pela União Nacional dos Dirigentes Municipais de Educação (UNDIME) e entregue ao MEC em setembro de 2016. Contudo, as contribuições, mais uma vez, parecem ter sido sistematizadas às pressas, tendo em vista os mais de 9 mil participantes e a agenda de seminários que em agosto ainda estavam sendo realizados em alguns estados. Sobre isso, destacam Bonini e Costa-Hübes (2020, p. 23) que o relatório "revelava uma leitura bastante enviesada das contri- 
buições propostas" e, nessa lógica, "foi criado um cenário para legitimar uma terceira versão, que viria a contrapelo das duas anteriores, pelo menos em alguns aspectos".

A terceira versão, com as etapas Educação Infantil e Ensino Fundamental, foi entregue ao Conselho Nacional de Educação (CNE) em abril de 2017 e aprovada em dezembro daquele mesmo ano. De julho a setembro, a sociedade pôde participar da consulta pública e enviar suas contribuições sobre a versão apresentada. Porém, em agosto, em meio ao processo de consulta pública e sem ao menos o documento ter sido aprovado, um guia de implementação da BNCC foi lançado. Meses depois, em dezembro de 2017, essa terceira e última versão foi aprovada e homologada pelo ministro da educação, Mendonça Filho. Em virtude das adequações exigidas pela Lei 13.415/2017, que impôs a Reforma do Ensino Médio, o processo de elaboração da BNCC só foi concluído um ano depois, quando da aprovação e homologação da última etapa da Educação Básica pelo então ministro da educação, Rossieli Soares.

De acordo com os excertos a seguir, coletados nos sites do MEC e Movimento pela Base, bem como no próprio texto que compreende o documento, pode-se constatar que o cenário de legitimação do documento é constituído, em grande medida, por discursos que citam o cará- ter colaborativo do processo de elaboração da BNCC e a suposta participação extensiva da sociedade:

concluída após amplos debates com a sociedade e os educadores do Brasil [...] (BRASIL, 2018, p. 5);

sua formulação, sob coordenação do MEC, contou com a participação dos Estados do Distrito Federal e dos Municípios, depois de ampla consulta à comunidade educacional $\mathrm{e}$ à sociedade (BRASIL, 2018, p. 20);

a Base foi elaborada em cumprimento às leis educacionais vigentes no País e contou com a participação de variadas entidades, representativas dos diferentes segmentos envolvidos com a Educação Básica nas esferas federal, estadual e municipal, das universidades, escolas, instituições do terceiro setor, professores e especialistas em educação brasileiros e estrangeiros (BRASIL, 2020, grifos nossos);

o processo de elaboração e redação da BNCC da Educação Infantil e do Ensino Fundamental durou cerca de três anos e teve como base a construção colaborativa, respeitando as leis educacionais vigentes no país (MOVIMENTO PELA BASE, 2020, grifos nossos).

Levando em consideração os acontecimentos em torno da elaboração do documento, essa participação, de fato, parece ter sido oportunizada. No entanto, isso não garante que as contribuições realizadas tenham sido consideradas conforme assegurado pelos diferentes agentes envolvidos em cada etapa desse conturbado processo. Nesse sentido, há um entendimento de que a versão aprovada e homologada em dezembro de 2017 se encontra bastante diferente da versão debatida nas audiências públicas regionais. Inclusive, algumas pesquisas, como 
a de Szundy (2019), propõem análises comparativas entre as versões apresentadas e indicam, sobretudo, o abandono de temas integradores "relevantes para a compreensão e transformação do mundo em que vivemos, tais como economia, sustentabilidade, direitos humanos, culturas indígenas e africanas, entre outros, para focar no desenvolvimento de competências e habilidades" (SZUNDY, 2019, p. 131).

Além do abandono de temas integradores, segundo Bonini e Costa-Hübes (2020), Macedo (2014), Freitas (2016), dentre outros, também há questões que raramente foram/são mencionadas acerca da elaboração da BNCC e seguem apagadas das discussões sobre o documento agora já em fase de implementação. A principal delas diz respeito à influência dos agentes privados em sua construção, já que foram estabelecidas parcerias entre setores do MEC e fundações e institutos privados que atuam no contexto educacional, entre os quais "havia perspectivas distintas e um embate de forças" (BONINI; COSTA-HÜBES, 2020, p. 25). Conforme destaca Macedo (2014, p. 1540) antes mesmo da elaboração da primeira versão, os sites dos principais agentes públicos que dinamizaram o debate em torno da construção da BNCC, CONSED e UNDIME, indicam praticamente os mesmos "parceiros" do setor privado: empresas, instituições financeiras, fundações e organizações não governamen- tais. Freitas (2016) pontua que, dentre Itaú Unibanco, Bradesco, Santander, Gerdau, Natura, Fundação Victor Civita, Fundação Roberto Marinho, Todos pela Educação e diversos outros, despontou, com protagonismo, a Fundação Lemann - uma das instituições que integra o grupo Movimento pela Base -, de Jorge Paulo Lemann (considerado o segundo homem mais rico do Brasil pelo ranking de 2020 da Forbes $^{5}$ ), bem como atores internacionais parceiros dessa fundação: "esses agentes estavam presentes nos seminários e encontros que discutiam a organização da BNCC [...], pois muitos desses encontros eram financiados ou coordenados pelas grandes fundações como forma de influenciar no processo" (BONINI; COSTA-HÜBES, 2020, p. 25).

Imbricada à interferência de agentes privados no processo de construção do documento, outra questão que merece destaque diz respeito aos interesses neoliberais e, consequentemente, ao foco do ensino voltado para padrões de avaliação. Segundo Macedo (2014), o vínculo entre a BNCC e a avaliação não pode ser negligenciado, porque a participação de agentes privados nesse processo tem como objetivo produzir "uma narrativa hegemônica sobre o que é qualidade na educação e sobre como atingi-la" (MACEDO, 2014, p. 1545). Nessa perspectiva, a preocupação em torno da proposta de uma BNCC reside, sobretudo, no desempenho dos estudan- 
tes em avaliações de nível nacional e internacional, já que, como destaca David Chaves, em reportagem à revista Poli da Fiocruz, tanto para o governo, quanto para o setor empresarial, é fundamental um alinhamento da BNCC às diretrizes do Programa Internacional de Avaliação de Alunos (Pisa), "uma vez que os países que têm destaque nessa avaliação são classificados pela OCDE como aqueles que investem numa educação de qualidade e terão mão de obra qualificada, o que possibilita a atração de investimento externo" (ANTUNES, 2017, p. 7).

Esses interesses pautados na ideologia neoliberal justificam, em grande medida, a adoção das noções de competências e habilidades, que até a segunda versão do documento pareciam focalizar a educação em uma perspectiva mais social, já que eram denominadas, respectivamente, direitos e objetivos de aprendizagem $^{6}$. Tais termos - sob os quais as etapas Ensino Fundamental e Ensino Médio estão fundamentadas - são amplamente empregados em contextos como o da educação profissional técnica e, por si só, já indicam uma perspectiva voltada para a ação no mundo do trabalho. Na BNCC,

[...] ser competente em algo é tratado como um "direito" e envolve a ideia de transferência de conhecimentos aprendidos em sala de aula para outras e mais amplas instâncias sociais. Mas essa transferência se dá com a finalidade de resolver problemas em um mundo já dado, cuja construção não envol- veu a participação das pessoas, e nem pressupõe qualquer ação de problematização da forma como esse mundo foi construído. Assim, mesmo que se considere a competência como pré-requisito para alguma ação humana inteligente, essa ação é epidérmica, já que, em sua estrutura, baseia-se numa posição passiva da pessoa diante dos fatos do mundo. Em outras palavras: competência é a propriedade de a pessoa agir resolvendo problemas propostos por outras pessoas, para que tudo à sua volta continue da mesma forma (GERHARDT, 2019, p. 87).

Além disso, principalmente as habilidades, por estarem descritas em listas e serem definidas como as "aprendizagens essenciais que devem ser asseguradas aos estudantes" (BRASIL, 2018, p. 29), podem ser entendidas como meio para controlar e comparar resultados de escolas em avaliações externas, estimular a competitividade entre elas e cobrar, com base em "evidências", aquelas que não obtiverem bons desempenhos, isto é, que não seguirem rigorosamente tudo que está sendo determinado pelo documento. Estratégias como essas coincidem com ideais econômicos de produtividade e controle e justificam a adoção de princípios "para trabalhar a formação de condutas nos estudantes, que corroborem com as necessidades estabelecidas pelos agentes privados, principalmente no que diz respeito à mão de obra para o mercado empresarial" (BONINI; COSTA-HÜBES, 2020, p. 29), porque focalizam muito mais a formação de cidadãos competentes e hábeis para o "pleno exercício da cidadania e do mundo 
do trabalho" (BRASIL, 2018, p. 8 e 13), deixando em segundo plano a formação crítica, que deveria ser a principal preocupação da escola.

À vista de todas as questões levantadas, é importante salientar a influência do documento no contexto educacional (representada na Figura 1), pois, a fim de justificar sua pertinência, os agentes responsáveis pela elaboração da atual versão da BNCC argumentam que ela "vai contribuir para o alinhamento de outras políticas e ações na educação [...], referentes à formação de professores, à avaliação, à elaboração de conteúdos educacionais e aos critérios para a oferta de infraestrutura adequada" (BRASIL, 2018, p. 8).

Figura 1 - Políticas educacionais influenciadas pela BNCC

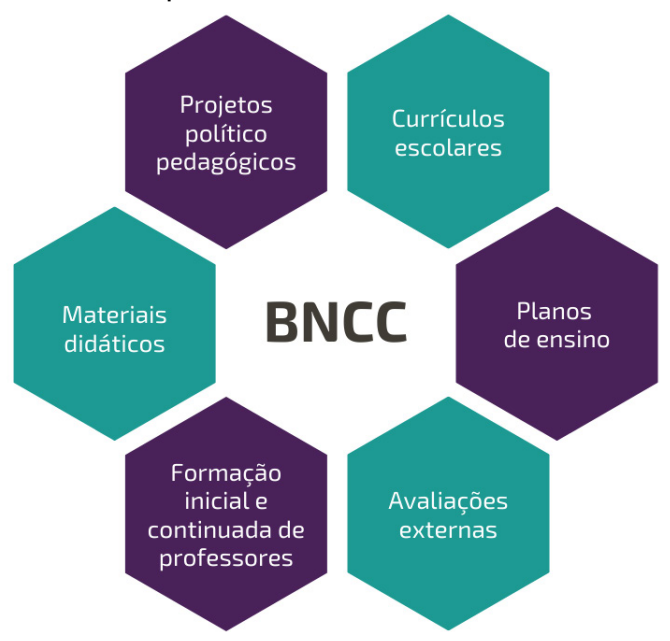

Fonte: Schmitt (2021, p. 85).
Desse modo, será a BNCC, em grande medida, a responsável pelas próximas mudanças no contexto educacional, visto que ela incide sobre planejamentos escolares (currículos e projetos político-pedagógicos), planos de ensino desenvolvidos por professores, avaliações nacionais e internacionais de larga escala, cursos superiores de licenciatura, cursos de formação continuada de professores bem como livros e demais materiais didáticos - apenas para citar os mais imediatos -, que já estão sendo adequados e/ou reelaborados à luz do documento.

Ainda que todas essas influências levem à padronização curricular da educação básica e, conforme pontuam Santos e Diniz-Pereira (2016, p. 295), possam reduzir as oportunidades educacionais dos estudantes e a autonomia docente, negar o direito à diferença e desrespeitar as diversidades culturais, buscar um caminho fácil para um processo complexo, que não se resolve com medidas simplistas, e configurar-se como uma solução barata para substituir a soma de investimentos que a educação necessita. Na opinião dos grupos favoráveis à versão aprovada, conforme introdução da atual versão do documento (BRASIL, 2018), a BNCC é entendida como peça central para alcançar a aprendizagem de qualidade, é um documento completo e contemporâneo, que corresponde às demandas do estudante desta época e, por meio dele, estará sendo cumprido o "compromisso 
da equidade que a sociedade brasileira espera" (BRASIL, 2018, p. 7).

Nesse sentido, com base nas questões apresentadas, constatamos uma tensão entre discursos com posições antagônicas sobre o que seria considerado ideal para a educação no país. Essa tensão parece resultar, em grande medida, de um cenário de disputa de interesses, marcado pela participação de agentes com diferentes posições político-ideológicas no processo de produção do documento, bem como pela influência desses agentes não apenas na construção da BNCC, mas também em seu processo de implementação. As análises apontam, ainda, que o contexto de crise política e as alterações compulsórias advindas do novo governo brasileiro influenciaram, nesse sentido, o fortalecimento desses conflitos, os quais, considerando a relação intrínseca entre texto e contexto, refletem, em alguma medida, nos discursos que orientam a fundamentação pedagógica do componente curricular Língua Portuguesa na BNCC do Ensino Fundamental.

\section{Análise e discussão dos resultados: fundamentos pedagógicos}

A fundamentação pedagógica apresenta conceitos importantes para o processo de ensino e aprendizagem de língua portuguesa no Ensino Fundamental e propõe categorias organizacionais para o componente curricular (SCHMITT, 2021). Nesse sentido, o componente mobiliza categorias como: campos de atuação, práticas de linguagem, objetos de conhecimento, anos/blocos de anos escolares e habilidades. Embora não estejam apresentadas de modo ordenado e linear na fundamentação pedagógica, essas categorias se propõem a organizar o componente curricular em termos pedagógicos e, em última instância, visam ao desenvolvimento das competências específicas e gerais propostas no documento.

Figura 2 - Organização do componente curricular Língua Portuguesa

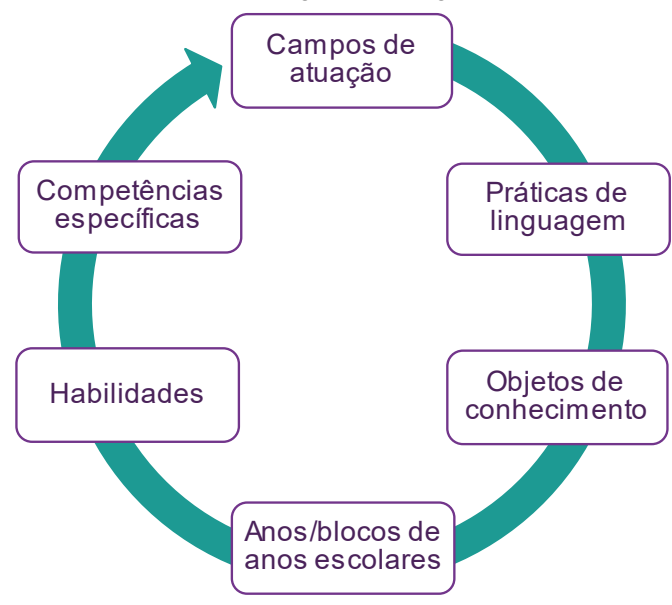

Fonte: Schmitt (2021, p. 87).

Em consonância com as categorias adotadas para organizar o componente curricular, a discussão analítica proposta nesta seção parte de um dos conceitos teóricos mais importantes que orientam o ensino de língua portuguesa no do- 
cumento: gêneros textuais/discursivos. Tendo em vista as 71 ocorrências do lexema no corpus, há pistas significativas de uma perspectiva de ensino como gênero(s), considerando a categoria de campos de atuação e tendo em vista que o texto é assumido como "unidade de trabalho [...], de forma a sempre relacionar os textos a seus contextos de produção [...]" (BRASIL, 2018, p. 67, grifos nossos). A respeito desse excerto e das ocorrências do lexema gênero(s), embora tenhamos constatado que o texto se mantém em posição de destaque no trabalho com a língua(gem), entendemos que essas evidências sinalizam o texto como unidade de análise. No entanto, apesar de o texto ser assumido como unidade de ensino, o que é bastante pertinente, há um significativo apagamento do gênero enquanto objeto de ensino, que é recorrente ao longo dos fundamentos pedagógicos e vai de encontro à proposta de organização do componente, que entende a categoria de campos de atuação como ponto de partida para a seleção de gêneros, práticas de linguagem e objetos de conhecimento. Esse apagamento pode ser comprovado ao analisarmos as ocorrências do lexema gênero(s), visto que, em diversas delas, o foco não é o gênero, mas sim o texto, que ocorre explicitamente em 33 dos 71 excertos analisados. Em pelo menos 13 dos 33 casos, tais ocorrências estão relaciona- das às condições de produção, circulação e/ou recepção ${ }^{7}$ dos textos:

Excerto 1: "Relacionar o texto com suas condições de produção, seu contexto sócio-histórico de circulação e com os projetos de dizer: leitor e leitura previstos, objetivos, pontos de vista e perspectivas em jogo, papel social do autor, época, gênero do discurso e esfera/campo em questão etc." (BRASIL, 2018, p. 72).

Excerto 2: "Reconstrução e reflexão sobre as condições de produção e recepção dos textos pertencentes a diferentes gêneros e que circulam nas diferentes mídias e esferas/ campos de atividade humana." (BRASIL, 2018, p. 73).

Excerto 3: "Analisar as condições de produção do texto no que diz respeito ao lugar social assumido e à imagem que se pretende passar a respeito de si mesmo; ao leitor pretendido; ao veículo ou à mídia em que o texto ou produção cultural vai circular; ao contexto imediato e ao contexto sócio-histórico mais geral; ao gênero do discurso/ campo de atividade em questão etc."(BRASIL, 2018, p. 77).

Excerto 4: "Consideração e reflexão sobre as condições de produção dos textos que regem a circulação de diferentes gêneros nas diferentes mídias e campos de atividade humana." (BRASIL, 2018, p. 77).

Como podemos observar nos excertos ${ }^{8}$, os aspectos sociocomunicativos são bastante focalizados, o que é fundamental para um trabalho que objetiva o estudo da linguagem em sua dimensão discursiva. Em contrapartida, nessas ocorrências relacionadas aos contextos de produção, circulação e/ou recepção, há um destaque para o lexema texto(s) que, como consequência, pode levar à compreensão de que os gêneros correspondem simplesmente 
a um contexto mais geral do texto ou a uma categoria do texto, ou seja, pode levar à compreensão de que trabalhar com gêneros é sinônimo de trabalhar, apenas, aspectos sociocomunicativos (contexto de situação). Entendemos que, em dado momento, o texto precisa ser focalizado enquanto unidade de análise e seja necessário fragmentá-lo para explorar determinados objetos de conhecimento. Porém, quando se trata de focalizar a dimensão contextual, imprescindível para explorar muitos dos objetos de conhecimento indicados para o componente e desenvolver o que seria esperado na prática de linguagem Análise Linguística/ Semiótica, o gênero não poderia ser minimizado, porque "os textos se realizam em gêneros, que, por sua vez, determinam marcas interacionais na materialidade textual" (SILVA, 2011, p. 31).

Relacionado a isso, identificamos, em pelo menos 10 ocorrências do lexema gêneros(s), que texto(s) está sendo destacado como pertencente a um gênero ou a gêneros de diversos campos da atividade humana:

Excerto 5: "o texto ganha centralidade na definição dos conteúdos, habilidades e objetivos, considerado a partir de seu pertencimento a um gênero discursivo [...]." (BRASIL, 2018, p. 67).

Excerto 6: "[...] ampliar a compreensão de textos que pertencem a esses gêneros e a possibilitar uma participação mais qualificada do ponto de vista ético, estético e político nas práticas de linguagem da cultura digital.”(BRASIL, 2018, p. 73).
Excerto 7: "Como já ressaltado, na perspectiva da BNCC, as habilidades não são desenvolvidas de forma genérica e descontextualizada, mas por meio da leitura de textos pertencentes a gêneros que circulam nos diversos campos de atividade humana." (BRASIL, 2018, p. 75).

Excerto 8: "Orquestrar as diferentes vozes nos textos pertencentes aos gêneros literários, fazendo uso adequado da "fala" do narrador, do discurso direto, indireto e indireto livre." (BRASIL, 2018, p. 77).

Nos excertos selecionados para demonstrar as ocorrências citadas, constatamos que o texto se mantém em posição proeminente, reforçando seu enfoque no trabalho com a língua(gem) e certo apagamento do gênero como norteador do processo de ensino e aprendizagem. Ainda, identificamos três itens lexicais de mesmo radical (pertencimento, pertencem e pertencentes) que, em certa medida, comprovam a escolha consciente de lexemas que indicam a relação entre texto e gênero como mero pertencimento e, desse modo, tomam o gênero como "ambiente" em que os textos ocorrem. Essa noção acaba fragmentando um conceito muito mais complexo que essa simples relação de pertencimento, uma vez que, conforme Bakhtin (1997, p. 279), gêneros discursivos referem-se a tipos relativamente estáveis de enunciados, concretos e únicos, elaborados por diferentes esferas de utilização da língua (BAKHTIN, 1997, p. 279), ou seja, eles se constituem, justamente, a partir da união entre concreto e abstrato, entre texto e contexto. 
Em pelo menos 21 ocorrências, o lexema gênero(s) também é evidenciado como práticas de linguagem. Dessas ocorrências, 6 delas enfatizam práticas de linguagem contemporâneas, que privilegiam gêneros da esfera digital. Outros casos, com menos ocorrências, destacam práticas de linguagem consagradas, menos institucionalizadas, mais institucionalizadas, familiares ou novas. Os excertos a seguir demonstram algumas das ocorrências mencionadas:

Excerto 9: "As práticas de linguagem contemporâneas não só envolvem novos gêneros e textos cada vez mais multissemióticos e multimidiáticos, [...]." (BRASIL, 2018, p. 68).

Excerto 10: "Conhecer e refletir sobre as tradições orais e seus gêneros, considerando-se as práticas sociais em que tais textos surgem e se perpetuam, bem como os sentidos que geram." (BRASIL, 2018, p. 79). Excerto 11: "Os campos de atuação considerados em cada segmento já contemplam um movimento de progressão que parte das práticas mais cotidianas em que a circulação de gêneros orais e menos institucionalizados é maior (Campo da vida cotidiana), em direção a práticas e gêneros mais institucionalizados, com predomínio da escrita e do oral público (demais campos)." (BRASIL, 2018, p. 84).

Excerto 12: "Será dada ênfase especial a procedimentos de busca, tratamento e análise de dados e informações e a formas variadas de registro e socialização de estudos e pesquisas, que envolvem não só os gêneros já consagrados, como apresentação oral e ensaio escolar, como também outros gêneros da cultura digital [...]." (BRASIL, 2018, p. 138).
Nos excertos selecionados, o discurso sobre ensino de gênero(s) como práticas de linguagem orais ou menos institucionalizadas (Excertos 10 e 11), mais institucionalizadas (Excerto 11), já consagradas pela escola (Excerto 12) e, principalmente, contemporâneas ou da cultura digital (Excertos 9 e 12), encaminha a identificação de outras 14 ocorrências que destacam a diversidade ou repertório de gêneros textuais/discursivos, como pode ser observado nos excertos a seguir:

Excerto 13: "A demanda cognitiva das atividades de leitura deve aumentar progressivamente desde os anos iniciais do Ensino Fundamental até o Ensino Médio. Esta complexidade se expressa pela articulação: da diversidade dos gêneros textuais escolhidos e das práticas consideradas em cada campo [...]." (BRASIL, 2018, p. 75).

Excerto 14: "A participação dos estudantes em atividades de leitura com demandas crescentes possibilita uma ampliação de repertório de experiências, práticas, gêneros e conhecimentos que podem ser acessados diante de novos textos, configurando-se como conhecimentos prévios em novas situações de leitura." (BRASIL, 2018, p. 75).

Excerto 15: "Assim, se fizer mais sentido que um gênero mencionado e/ou habilidades a ele relacionadas no $9^{\circ}$ ano sejam trabalhados no $8^{\circ}$, isso não configura um problema, desde que ao final do nível a diversidade indicada tenha sido contemplada." (BRASIL, 2018, p. 75-76).

Excerto 16: "Outros gêneros, além daqueles cuja abordagem é sugerida na BNCC, podem e devem ser incorporados aos currículos das escolas [...]." (BRASIL, 2018, p. 139).

Conforme os excertos 9 a 16, embora a perspectiva de ensino como gênero(s) 
seja reafirmada, tendo em vista a preocupação em possibilitar um trabalho que considere o contato com diferentes e diversas esferas da atividade humana, evidencia-se um discurso, em grande medida, voltado para a ampliação do repertório. Nesse sentido, parece não haver um destaque para o ensino sistematizado de gêneros, mas sim para o trabalho com uma variedade de gêneros ${ }^{9}$. Essa constatação é confirmada, principalmente, no excerto 15 , quando se destaca que a diversidade indicada deve ser contemplada mesmo que um gênero não tenha sido trabalhado no ano em que fora indicado pelos campos de atuação e habilidades propostas.

Relacionado às ocorrências de gênero(s) como situações comunicativas, em pelo menos outros 7 casos, o lexema também parece estar associado a esferas da atividade humana, que pertencem aos diferentes campos de atuação. Os excertos selecionados apresentam alguns dos "grupos" de gêneros destacados (gêneros jornalísticos, informativos, opinativos, publicitários, legais, normativos, reivindicatórios, propositivos, narrativos e poéticos):

Excerto 17: "No primeiro campo, os gêneros jornalísticos - informativos e opinativos - e os publicitários são privilegiados, com foco em estratégias linguístico-discursivas e semióticas voltadas para a argumentação e persuasão. "(BRASIL, 2018, p. 136).

Excerto 18: "No campo de atuação da vida pública ganham destaque os gêneros legais e normativos [...] sempre tomados a partir de seus contextos de produção o que contextualiza e confere significado a seus preceitos." (BRASIL, 2018, p. 137).

Excerto 19: "Ainda nesse campo, estão presentes gêneros reivindicatórios e propositivos e habilidades ligadas a seu trato." (BRASIL, 2018, p. 138).

Excerto 20: "Para tanto, as habilidades, no que tange à formação literária, envolvem conhecimentos de gêneros narrativos e poéticos que podem ser desenvolvidos em função dessa apreciação e que dizem respeito, no caso da narrativa literária, a seus elementos [...].” (BRASIL, 2018, p. 138).

Como podemos constatar a partir dos excertos, há um discurso sobre ensino de gênero(s) bastante amplo, que focaliza seus domínios discursivos. Ainda que determinados gêneros pertençam a um mesmo campo ou esfera, todos eles apresentam especificidades que poderiam ser consideradas no desenvolvimento das aprendizagens. Focalizar gêneros de forma tão ampla pode levar a abordagens de ensino que focalizem textos enquanto exemplares de gêneros de forma superficial e desconsiderem as características particulares dos diferentes gêneros, motivadas por aspectos sociocomunicativos específicos de cada um deles.

Por sua vez, quando surge um discurso mais voltado para um ensino nessa perspectiva de gêneros enquanto objetos de ensino, o lexema está relacionado, em relativamente poucas ocorrências, à estrutura composicional (8 ocorrências), ao estilo (6 ocorrências) e ao conteúdo temático (3 ocorrências): 
Excerto 21: "Estabelecer relações entre as partes do texto, levando em conta a construção composicional e o estilo do gênero [...]." (BRASIL, 2018, p. 77).

Excerto 22: "No que tange ao estilo, serão levadas em conta as escolhas de léxico e de variedade linguística ou estilização e alguns mecanismos sintáticos e morfológicos, de acordo com a situação de produção, a forma e o estilo de gênero." (BRASIL, 2018, p. 80). Excerto 23: "Assim, no que diz respeito à linguagem verbal oral e escrita, as formas de composição dos textos dizem respeito à coesão, coerência e organização da progressão temática dos textos, influenciadas pela organização típica (forma de composição) do gênero em questão.” (BRASIL, 2018, p. 80). Excerto 24: "O Eixo da Análise Linguística/Semiótica envolve os procedimentos e estratégias (meta)cognitivas de análise e avaliação consciente [...] das materialidades dos textos, responsáveis por seus efeitos de sentido, seja no que se refere às formas de composição dos textos, determinadas pelos gêneros (orais, escritos e multissemióticos) e pela situação de produção, seja no que se refere aos estilos adotados nos textos, com forte impacto nos efeitos de sentido [...]." (BRASIL, 2018, p. 80).

Os excertos 21 a 24 focalizam a "for$\mathrm{ma} /$ construção composicional" e o "estilo" dos gêneros (além de outras 3 ocorrências, não apresentadas nos excertos, focalizarem também o conteúdo temático) e evidenciam que as características constituintes dos gêneros parecem estar sendo consideradas de forma isolada. Embora seja necessário, em determinadas situações de aprendizagem, considerar tais características isoladamente, como unidades de análise, entendemos que esse discurso pode levar a uma abordagem de ensino que não chegue ao todo complexo que constitui os gêneros, tendo em vista que, conforme Bakhtin (1997, p. 279), o enunciado reflete as condições específicas e as finalidades de diferentes esferas da atividade humana, não só por seu conteúdo temático e por seu estilo, mas também, e sobretudo, por sua construção composicional:

[...] estes três elementos (conteúdo temático, estilo e construção composicional) fundem-se indissoluvelmente no todo do enunciado, e todos eles são marcados pela especificidade de uma esfera de comunicação (BAKHTIN, 1997, p. 279).

Além disso, nenhuma das ocorrências analisadas mencionou, explicitamente, $o$ propósito comunicativo ou o objetivo do gênero, apenas uma delas mencionou a "função", lexema que, no entanto, não é utilizado nem tomado como sinônimo de propósito comunicativo (ASKEHAVE; NIELSEN, 2004). Essa evidência revela fragilidades a respeito de como o gênero está sendo abordado no documento, porque os propósitos comunicativos “[...] constituem a base lógica para o gênero. Essa base modela a estrutura esquemática do discurso, influencia e condiciona a escolha do conteúdo e do estilo [...]" (SWALES, 1990, p. 58, tradução nossa). Assim, as definições de gênero devem ser centradas "na ação que é usada para realizá-lo" (MILLER, 2012, p. 21), ou seja, centradas na ação social que decorre do seu propósito comunicativo. 
Especificamente nos excertos 23 e 24, essas características dos gêneros, como estrutura composicional e estilo, também ocorrem relacionadas ao lexema texto(s). Desse modo, nesses dois últimos excertos, parece haver certa divergência entre os discursos, visto que, no excerto 23 , destacam-se que "as formas de composição dos textos" são influenciadas pelas formas de composição dos gêneros e, no excerto 24, por sua vez, destaca-se que elas são determinadas por eles. No primeiro caso, a escolha lexical influenciadas acaba minimizando o gênero, enquanto no segundo, a partir do lexema determinadas, o gênero é destacado como norteador do processo de ensino e aprendizagem.

\section{Considerações finais}

Neste artigo, buscamos analisar criticamente os discursos sobre ensino de língua portuguesa manifestados nos fundamentos pedagógicos do componente na etapa Ensino Fundamental (anos finais) da BNCC (BRASIL, 2018). De modo geral, os fundamentos pedagógicos do componente curricular Língua Portuguesa remetem a uma perspectiva de ensino que focaliza o texto e o seu contexto. Verificamos, nesse sentido, que a BNCC apresenta uma concepção de ensino alinhada a pressupostos teórico-metodológicos que consideram contextos situados e diversos, o desenvolvimento de práticas de usos de língua(gem) e reflexões sobre esses usos, a compreensão crítica acerca dos textos e discursos que circulam nas diferentes esferas da sociedade, o desenvolvimento de práticas de leitura e produção textual articuladas pela prática de análise linguística, entre outros.

Apesar de emergir um discurso sobre o ensino de língua portuguesa no documento como gênero(s) discursivos / textuais, em muitas ocorrências há certa fluidez, visto que, em grande medida, o gênero surge como uma categoria ou contexto mais geral do texto. Assim, ainda que o documento assuma "a centralidade do texto como unidade de trabalho", sendo o texto o responsável pela "definição dos conteúdos, habilidades e objetivos" (BRASIL, 2018, p. 67), ao apresentar os campos de atuação como uma das principais categorias organizacionais do componente curricular, a fim de orientar "a seleção de gêneros, práticas, atividades e procedimentos em cada um deles" (BRASIL, 2018, p. 85), observa-se 0 apagamento do gênero enquanto objeto de ensino de Língua Portuguesa, o que pode suscitar leituras enviesadas do documento e, consequentemente, subsidiar propostas pedagógicas que não deem conta da complexidade desse objeto. É válido destacar ainda, com relação às fragilidades e incongruências evidenciadas em diversos pontos da discussão analítica, que elas parecem estar rela- 
cionadas a um problema mais geral da BNCC (e de outros exemplares do gênero documento oficial da educação), que se refere, justamente, ao limitado espaço destinado à abordagem teórico-metodológica de conceitos importantes para a prática pedagógica.

Ainda que não tenha o propósito comunicativo de divulgar conceitos, a BNCC pode ser considerada um documento de recontextualização científica, uma vez que, considerando a realidade educacional brasileira - especialmente a formação continuada de professores -, determinados conceitos circulam apenas na esfera acadêmica e muitos professores não tiveram contato ou oportunidade para estudá-los. Além disso, refletindo sobre a influência do documento face a outras políticas e ações educacionais, seria bastante válido que o documento sugerisse, por exemplo, leituras, notas de rodapé, citações e referências ao longo das discussões propostas. Essa sugestão, aliada às formações continuadas, auxiliaria os professores no processo de implementação do documento, pois, para que possam desenvolver propostas pedagógicas coerentes com as perspectivas que orientam o componente curricular, é imprescindível que tenham condições e aparato teórico-metodológico para fazê-lo.

\section{Pedagogical Foundations of Portuguese Language at BNCC: a critical discourse analysis}

\section{Abstract}

Considering the importance of the National Common Curricular Base and its influence on the development of pedagogical practices across the country, in this research report, we critically analyze the discourses on Portuguese language teaching present in the pedagogical foundation of the curricular component for the final years of Elementary School. Therefore, we are guided theoretically and methodologically by Critical Discourse Analysis, which proposes a three-dimensional analysis, with a view to the description of textual practice, the interpretation of the discursive practices and the explanation of social practices. The results points to a discourse on Portuguese language teaching largely aligned with the perspective of discursive/textual genres that considers situated contexts and focuses on the development of language usage practices. It is important to highlight a certain discursive fluidity, since, at times, genre is erased as a teaching object, which can give rise to biased readings of the document and, consequently, subsidize pedagogical proposals that do not contemplate the complexity of this object.

Keywords: National Common Curricular Base; Elementary School; Portuguese Language Teaching 


\section{Notas}

1 Nesta pesquisa focalizamos, exclusivamente, as ocorrências do item lexical gênero(s) textual(is) / discursivo(s).

2 A amostragem de análise selecionada compreende os excertos em que os lexemas considerados interessantes para a pesquisa ocorreram no corpus. Esses excertos foram localizados a partir da ferramenta find em software para leitura de documentos em PDF. Para viabilizar a busca, contagem e análise crítica das ocorrências, mantivemos, em um único arquivo, apenas as páginas do documento que compreendem os fundamentos pedagógicos.

3 Versões estão disponíveis para download no link: http://basenacionalcomum.mec.gov.br/ historico.

4 O relatório está disponível para download no link: http://basenacionalcomum.mec.gov.br/ relatorios.

5 Informação disponível em: https://forbes. com.br/listas/2020/09/10-maiores-bilionarios-brasileiros-em-2020/.

6 É válido mencionar, a respeito disso, que em consonância com a Resolução $\mathrm{n}^{\circ} 4$, de dezembro de 2018, "a expressão 'competências e habilidades' deve ser considerada como equivalente à expressão 'direitos e objetivos de aprendizagem' presente na Lei do Plano Nacional de Educação (PNE)" (Art $3^{\circ}$, parágrafo único), embora essa importante noção de sinonímia não tenha sido explicitamente mencionada no documento propriamente dito.

7 Mantemos a nomenclatura "recepção", adotada pela $\mathrm{BNCC}$, embora entendamos que se trata de um termo que nós, de acordo com a ACD, empregamos como "consumo".

8 Nos excertos apresentados nesta seção, deixamos em negrito os itens lexicais e sublinhamos características interessantes relacionadas a esses itens lexicais que indicam pistas linguísticas dos discursos sobre ensino como gênero(s) e como (multi)letramentos.

9 Conforme Glossário de gêneros e suportes textuais (PINTON; STEINHORST; BARRETO, 2020), mais de 80 diferentes gêneros são indicados para os anos finais do Ensino Fundamental, por exemplo "comentário, carta de leitor, post em rede social, gif, meme, fanfic, vlogs variados, political remix, charge digital, paródias de diferentes tipos, vídeos-minuto, e-zine, fanzine, fanvídeo, vidding, gameplay, walkthrough, detonado, machinima, trailer honesto, playlists comentadas de diferentes tipos etc." (BRASIL, 2018, p. 73).

\section{Referências}

ANTUNES, A. A quem interessa a BNCC? Revista POLI: saúde, educação e trabalho - jornalismo público para o fortalecimento da Educação Profissional em Saúde. Ano X, n. 54, p. 6-13, nov./dez, 2017.

ASKEHAVE, I.; NIELSEN, A. E. Web-mediated genres: a challenge to traditional genre theory. Working Papers, n. 6, p. 1-50, 2004.

AZEVEDO, I. C. M.; DAMACENO, T. M. S. Desafios da BNCC em torno do ensino de Língua Portuguesa na Educação Básica. Revista de Estudos de Cultura da UFS - Publicação do Núcleo de Estudos de Cultura, Universidade Federal de Sergipe, n. 7, 2017, p. 83-92.

BAKHTIN, M. Os gêneros do discurso. In: BAKHTIN, M. Estética da criação verbal. 2. ed. São Paulo: Martins Fontes, 1997, p. 277-326.

BARTON, E. Linguistic discourse analysis: how the language in texts works. In: BAZERMAN, C.; PRIOR, R. (Eds.) What writing does and how it does it: An introduction to analyzing texts and textual practices. Mawhaw, NJ: Lawrence Erlbaum, 2004, p. 57-82.

BONINI, A.; COSTA-HÜBES, T. C. O Contexto de produção da Base Nacional Comum Curricular (BNCC): cenas dos bastidores. In: COSTA-HÜBES, T. C.; KRAEMER, M. A. D. (Orgs.). Uma leitura crítica da Base Nacional Comum Curricular: Compreensões subjacentes. Mercado de Letras, 2020.

BRASIL. Base Nacional Comum Curricular: educação é a base (site). 2021. Disponível em: <http://basenacionalcomum.mec.gov. br/>. Acesso em: 20 jun. 2021.

BRASIL. Ministério da Educação. Base Nacional Comum Curricular. Brasília: MEC, 
2018. Disponível em: <http://basenacionalcomum.mec.gov.br>. Acesso em: 30 mar. 2021.

BRASIL. Ministério de Educação e do Desporto. Secretaria de Educação Fundamental. Parâmetros curriculares nacionais: terceiro e quarto ciclos do Ensino Fundamental: introdução aos parâmetros curriculares nacionais. Brasília: MEC/SEF, 1998.

FAIRCLOUGH, N. Analysing discourse: textual analysis for social research. London; New York: Routledge. 2003.

FAIRCLOUGH, N. Discurso e mudança social. Trad. Izabel Magalhães (Org.). Brasília: Universidade de Brasília, 2001.

FAIRCLOUGH, N. Language and power. London: Longman, 1989.

FREITAS, A. A Base Nacional Comum Curricular e a educação banqueira. Carta Capital, 2016. Disponível em: <https:// www.academia.edu/28265282>. Acesso em: 20 set. 2020.

GERHARDT, A. M. Concepções de aprendizado na BNCC: bases ideológicas e efeitos no ensino de português. In: GERHARDT, A. M.; AMORIM, M. A. (Org.). A BNCC e o ensino de línguas e literaturas. Pontes Editores, 2019. p. 87-120.

LOURENCO, D. G.; LINO DE ARAÚJO, D. A proposta de Análise linguística/ Semiótica na BNCC: a natureza dos objetos de conhecimento. Revista Eutomia: Recife, n. 23, v. 1, p. 88-107, 2019. Disponível em: <https:// periodicos.ufpe.br/ revistas/EUTOMIA/article/ view/241617/33806>. Acesso em: 20 jun. 2021.

MACEDO, E. Mas a escola não tem que ensinar?: conhecimento, reconhecimento e alteridade na teoria do currículo. Revista Currículo sem Fronteira, s, v. 17, n. 3, p. 539-554, set./dez. 2017.

MILLER, C. R. Comunidade retórica: a base cultural dos gêneros. In: DIONISIO, A. P.; HOFFNAGEL, J. C. (Org.). Gênero textual, agência e tecnologia: estudos. Tradução de Judith Chambliss Hoffnagel. São Paulo: Parábola Editorial, 2012. p. 43-55.

MOVIMENTO PELA BASE. Movimento pela Base Nacional Comum. 2021. Disponível em: <http://movimentopelabase.org. br/>. Acesso em: 20 jun. 2021.

PINTON, F. M.; STEINHORST, C.; BARRETO, T. Glossário de gêneros e suportes textuais: Base Nacional Comum Curricular. Santa Maria, RS: UFSM, CAL, NEPELIN, 2020.

RAMALHO, V.; RESENDE, V. M. Análise de Discurso Crítica. São Paulo: Contexto, 2006.

SANTOS, L. L. de C. P.; DINIZ-PEREIRA, J. E. Tentativas de padronização do currículo e da formação de professores no Brasil. Caderno Cedes, Campinas, v. 36, n. 100, p. 281-300, set./dez. 2016.

SCHMITT, R. M. Base Nacional Comum Curricular: Análise Crítica de Discursos sobre Ensino de Língua Portuguesa. 2021. Dissertação (Mestrado em Letras) - Universidade Federal de Santa Maria, Santa Maria, RS, 2021.

SILVA, W. R. Estudo da gramática no texto: demandas para o ensino e a formação do professor de língua materna. Maringá: Editora da Universidade Estadual de Maringá, 2011.

SWALES, J. Genre analysis: English in academic and research settings. Cambridge: Cambridge University Press, 1990.

SZUNDY, P. C. A Base Nacional Comum Curricular e a Lógica Neoliberal: que línguas(gens) são (des)legitimadas? In: GERHARDT, A. M.; AMORIM, M. A. (Orgs.). A BNCC e o ensino de línguas e literaturas. Pontes Editores, 2019. p. 121-151.

TÍLIO, R. Prefácio - A Base Nacional Comum Curricular e o contexto brasileiro. In: GERHARDT, A. M.; AMORIM, M. A. (Org.). A BNCC e o ensino de línguas e literaturas. Pontes Editores, 2019. p. 7-15. 